\title{
Pressure-induced inhibition of fast axonal transport of proteins in the rabbit vagus nerve in galactose neuropathy: prevention by an aldose reductase inhibitor
}

\author{
W.G. McLean \\ Department of Pharmacology and Therapeutics, University of Liverpool, Liverpool, UK
}

\begin{abstract}
Summary. Fast and slow anterograde axonal transport and retrograde axonal transport of proteins were studied in the mainly non-myelinated sensory fibres of the vagus nerve of rabbits fed a diet of $50 \%$ galactose over a period of 29 days. Galactose feeding had no effect on the rate or protein composition of slow transport nor on the amount of retrogradely transported proteins. There was a slight retardation of fast transported proteins although their composition was unchanged. The galactose feeding led to a significant increase $(p<0.005)$ in nerve water content and nerve galactitol but no significant change in myo-inositol. When $20 \mathrm{~mm} \mathrm{Hg}$ pressure was applied locally to the cervical vagus nerve, fast trans-
\end{abstract}

ported proteins accumulated proximal to the compression zone in the galactose-fed but not in control rabbits. Administration of the aldose reductase inhibitor Statil (ICI 128436) throughout the experiment prevented the increased susceptibility to pressure and the increase in nerve galactitol and water content. The effects of pressure are similar to those found in the streptozotocin-diabetic rat although the underlying mechanisms may differ.

Key words: Axonal transport, nerve compression, neuropathy, galactose, aldose reductase, Statil.
Streptozotocin-induced experimental diabetes in the rat leads to an increase in the inhibition of the fast axonal transport of proteins in the sciatic nerve by local compression [1]. This phenomenon is related to the intraneural accumulation in diabetes of the sugar alcohol sorbitol, since the increased inhibition of transport is prevented by administration of the aldose reductase inhibitor 'Statil' (ICI 128436) [2]. An experimental procedure that has been used to study the consequences of increased sugar alcohol accumulation is galactose feeding, which leads to increased intraneural levels of the polyol galactitol, with consequent osmotic changes leading to increased nerve water content and endoneurial fluid pressure [3, 4]. Similar increases in nerve polyols occur in diabetic neuropathy although the increase in nerve water content is either less pronounced, or absent [5-7].

It was the intention of this study to determine if galactose feeding could lead, like experimental diabetes, to an alteration in susceptibility to pressure and if the effect could also be produced in non-myelinated fibres. The rabbit vagus nerve was chosen since it contains a fairly homogeneous population of non-myelinated fibres in which it is possible to study various phases of axonal transport as well as the effects of applying mild local pressure $[8,9]$.

\section{Materials and methods}

Male albino rabbits $(2.6-3.6 \mathrm{~kg})$ were divided into four groups. The first group was fed a standard laboratory diet, while the second received a diet consisting of $50 \% \mathrm{D}$-galactose. The galactose diet was manufactured in the laboratory by mixing powdered galactose in a food blender with the standard diet moistened with an equal weight of water. The mixture was formed into bars and baked at $80^{\circ} \mathrm{C}$ until almost dry; a slightly moist galactose diet was found to be the most acceptable to the rabbits. The galactose-fed rabbits received their diet over a period of 29 days, during which time they had two breaks of 4 days each (days 8-11 and days 18-21) in which they received the standard diet. This was to prevent some slight weight loss observed in preliminary experiments. Both groups of rabbits were given water ad libitum. The galactose-fed rabbits showed no signs of neurological defects or any other abnormalities.

A third group of rabbits was fed a galactose-rich diet, as above, and also received a daily dose of $25 \mathrm{mg} / \mathrm{kg}$ Statil (ICI 128436; Imperial Chemical Industries plc, Macclesfield, UK) by gastric intubation. The fourth group received the same dose of Statil along with a normal diet.

Rabbits were anaestherised with Valium (diazepam) $1 \mathrm{mg} / \mathrm{kg}$ intramuscularly and Hypnorm (fentanyl $0.2 \mathrm{mg} / \mathrm{ml}$ and fluanisone $10 \mathrm{mg} / \mathrm{ml}) 0.5 \mathrm{ml} / \mathrm{kg}$ intramuscularly. The left or right nodose ganglion was exposed and the following procedures carried out on control and galactose-fed rabbits, without administration of Statil.

1. For electrophoretic analysis of fast axonally transported proteins, one nodose ganglion was exposed and 4 injections each of 1-2 $\mu \mathrm{l}$ totalling $150 \mu \mathrm{Ci}{ }^{35} \mathrm{~S}$-L-methionine $(1200 \mathrm{Ci} / \mathrm{mmol}$; Amersham, Amersham UK) were made subepineurally into the ganglion. Animals were killed $5 \mathrm{~h}$ later and the vagus nerves and nodose ganglia 
removed. For measurement of the rate and amount of fast transport, a total of $60 \mu \mathrm{Ci}{ }^{3} \mathrm{H}$-L-leucine $(60 \mathrm{Ci} / \mathrm{mmol}$; Amersham) were injected into one nodose ganglion. Animals were killed $3.5 \mathrm{~h}$ later and vagus nerves and nodose ganglia removed.

2. For measurement of slow axonal transport, ${ }^{35}$ S-methionine was injected as in 1) but animals were killed and nerves and ganglia were removed $56 \mathrm{~h}$ after radiolabelling.

3. For measurement of retrograde axonal transport, a total of $60 \mu \mathrm{Ci}$ ${ }^{3} \mathrm{H}$-L-leucine were injected into one nodose ganglion. The animals were reanaesthetised $16 \mathrm{~h}$ later and a pair of ligatures $5 \mathrm{~mm}$ apart were applied to the radiolabelled nerve at mid-cervical level. After a further $8 \mathrm{~h}$ the animals were killed and nerves and ganglia removed.

The following procedure was carried out on control and galactose-fed rabbits, both with and without administration of Statil.

4. For measurement of the effects of applied pressure: $2 \mathrm{~h}$ after radiolabelling with ${ }^{3} \mathrm{H}$-leucine as in 3 , the cervical vagus nerve was exposed and a small perspex compression chamber applied to the nerve, as described previously [10]. The chamber consisted of two halves to which were attached rubber membranes which could be inflated with nitrogen to a desired pressure - in this case $20 \mathrm{~mm} \mathrm{Hg}$. The two halves of the chamber were fastened around the nerve and remained in place for a further $2 \mathrm{~h}$. The animals were then killed and nerves and ganglia removed.

In 2. and 3. above the animals were placed on their respective diets during the course of the experiment.

Radiolabelled nerves were frozen for storage and thereafter cut into pieces. For nerves radiolabelled with ${ }^{3} \mathrm{H}$-leucine, $2.5 \mathrm{~mm}$ pieces were washed twice in $10 \%$ trichloroacetic acid and then dissolved in Soluene (Packard, Reading, UK) at room temperature prior to liquid scintillation counting of the TCA-insoluble radioactivity. For nerves radiolabelled with ${ }^{35} \mathrm{~S}$-methionine, $5 \mathrm{~mm}$ pieces of nerve were homogenised in a buffer containing sodium dodecyl sulphate (SDS), applied consecutively to wells of a gradient SDSpolyacrylamide gel and electrophoresed. The resulting gels were dried, impregnated with fluor and applied to X-ray film to produce fluorographs. The procedure has been described in detail previously [11].

The contralateral non-radiolabelled nerves were cleaned, blotted dry of excess moisture and weighed. They were then freeze-dried to constant weight and reweighed, in order to obtain a measure of nerve water content. In one experiment, the dried nerves were reconstituted in water and processed for measurement of galactitol and myo-inositol by the method of Stribling et al. [12] with the inclusion of galactose and galactitol as standards.

\section{Calculation of results}

Fast transport. The apparent rate of fast transport was measured both from the position of the front of the wave of radioactive proteins and from the position of the peak of radioactive proteins in the nerve $3.5 \mathrm{~h}$ after radiolabelling, assuming a 'lag-time' between radiolabelling and initiation of fast transport of $30 \mathrm{~min}$ [8]. The amount of fast transported radiolabelled proteins in the nerve was expressed as a fraction of that in the nodose ganglion. The main comparison of interest was of the proteins present in the most proximal portions of the nerve, 20-35 $\mathrm{mm}$ from the ganglion.

Slow transport. The rate of slow transport was calculated from the position of the fronts of the waves of slowly transported proteins in the nerve $56 \mathrm{~h}$ after radiolabelling.

Retrograde transport. The amount of proteins in the nerve immediately proximal to the proximal ligature and distal to the distal ligature were expressed as a fraction of the total amount of radioactive proteins in the nerve between 40 and $50 \mathrm{~mm}$ from the ganglion [13]. The latter figure was a measure of retrograde axonal transport while the former was a measure of the amount of fast transported proteins in the nerve once the initial wave of fast radiolabelled proteins had passed that point [11].
Inhibition by compression. The susceptibility of fast transport to compression was calculated as a Transport Block Ratio, i.e. the ratio of radioactive proteins in the two nerve pieces immediately proximal to the compression site plus one nerve piece within it, to the total radioactivity in the nerve between 37.5 and $50 \mathrm{~mm}$ from the ganglion [8].

\section{Statistical analysis}

A non-parametric statistical test (Mann-Whitney) was used for comparison of axonal transport measurements between control and galactose-fed rabbits. Student's t-test was used for comparison of the direct measurements of nerve galactitol, myo-inositol and water content.

Unless otherwise stated, all chemicals were obtained from Sigma, Poole, UK or British Irug Houses, Poole, UK.

\section{Results}

\section{Fast axonal transport}

The apparent mean rate of fast transport in control rabbits calculated from the position of the front of the wave of radiolabelled proteins, was $14.8 \pm 1.0 \mathrm{~mm} / \mathrm{h}$ (mean $\pm \mathrm{SD} ; n=5$ ). In the galactose-fed animals the apparent rate was slightly less at $13.0 \pm 1.0 \mathrm{~mm} / \mathrm{h}$ $(n=5)$, as shown in Table 1 . The difference was statistically significant at the $p<0.05$ level. The apparent mean rates, as calculated from the peaks of the waves of radiolabelled proteins were $8.5 \pm 0.4 \mathrm{~mm} / \mathrm{h}$ and $8.3 \pm 2.4 \mathrm{~mm} / \mathrm{h}$, respectively. The difference was not significant. The amount of fast transported radiolabelled proteins within the nerves expressed in terms of radioactive proteins within the ganglion, was greater in galactose-fed than control animals. The increase was maximal when the proteins present in the nerve $25-30 \mathrm{~mm}$ from the ganglia were analysed (Table 1; $p<0.01$ ). When the accumulation of delayed fast transported proteins was measured (as outlined above under 'Retrograde transport') there was no significant difference between control and galactose-fed rabbits (Table 1).

Vagus nerve galactitol levels in those animals were below the level of detection of the assay (i.e. < $0.08 \mu \mathrm{g} / \mathrm{g}$ wet weight). The mean galactitol level in the nerves of the rabbits used for the measurement of fast transport rate was $53.0 \pm 50.0 \mu \mathrm{g} / \mathrm{g}$. Despite the variation, this was significantly higher than the level in the control rabbits $(p<0.05)$. Myo-inositol levels were not significantly reduced (Table 2 ).

Fluorograms of fast-transported ${ }^{35} \mathrm{~S}$-radiolabelled proteins failed to show any difference between the control and galactose animals in the nature of the fast transported proteins. In both cases they were similar to previously published work [11] and for that reason are not shown.

\section{Retrograde transport}

The amount of radioactive proteins accumulating distal to a ligature on the vagus nerve did not differ be- 
Table 1. Axonal transport in control and galactose-fed rabbits

\begin{tabular}{|c|c|c|c|c|c|c|c|}
\hline \multirow{2}{*}{$\begin{array}{l}\text { Measurement } \\
\text { A. Fast transport } \\
\text { rate }(\mathrm{mm} / \mathrm{h})\end{array}$} & \multicolumn{2}{|c|}{$\begin{array}{l}\text { Galactose- } \\
\text { fed }\end{array}$} & \multirow{2}{*}{$\begin{array}{l}n \\
-5\end{array}$} & \multicolumn{2}{|c|}{ Control } & \multirow{2}{*}{$\begin{array}{c}n \\
5\end{array}$} & \multirow{2}{*}{$\frac{p}{<0.05}$} \\
\hline & 13.0 & \pm 1.0 & & 14.8 & \pm 1.0 & & \\
\hline $\begin{array}{l}\text { B. Fast transport } \\
\text { rate }(\mathrm{mm} / \mathrm{h})\end{array}$ & 8.3 & \pm 2.4 & 5 & 8.5 & \pm 0.4 & 5 & NS \\
\hline $\begin{array}{l}\text { C. Amount of fast } \\
\text { transported } \\
\text { proteins }\end{array}$ & 0.03 & \pm 0.014 & 5 & 0.017 & \pm 0.005 & 5 & $<0.01$ \\
\hline $\begin{array}{l}\text { D. Anterograde } \\
\text { transport } \\
\text { accumulation }\end{array}$ & 4.49 & \pm 0.51 & 5 & 3.43 & \pm 0.78 & 4 & NS \\
\hline $\begin{array}{l}\text { E. Slow transport } \\
\text { rate }(\mathrm{mm} / \text { day) }\end{array}$ & 23.1 & \pm 2.1 & 4 & 23.8 & $\pm 5.8^{\mathrm{a}}$ & 5 & NS \\
\hline $\begin{array}{l}\text { F. Retrograde } \\
\text { transportion } \\
\text { accumulation }\end{array}$ & 1.19 & \pm 0.14 & 5 & 1.12 & \pm 0.34 & 4 & NS \\
\hline
\end{tabular}

Measurements of axonal transport in rabbit vagus nerve after feeding of $50 \%$ galactose for a period of 29 days, mean of $n$ values \pm SD mean, as calculated from:

A. The distance from the nodose ganglion of the front of the wave of ${ }^{3} \mathrm{H}$-labelled proteins $3.5 \mathrm{~h}$ after radiolabelling, assuming a delay for protein synthesis of $30 \mathrm{~min}$.

B. The distance from the nodose ganglion of the peak of the wave of ${ }^{3} \mathrm{H}$-labelled proteins $3.5 \mathrm{~h}$ after radiolabelling, assuming a delay for protein synthesis of $30 \mathrm{~min}$.

C. The ratio of the radioactive proteins in nerve pieces $20-35 \mathrm{~mm}$ from the nodose ganglion to the radioactive proteins in the ganglion $3.5 \mathrm{~h}$ after radiolabelling.

D. The ratio of the radioactive proteins in the two $2.5 \mathrm{~mm}$ nerve pieces immediately proximal to a pair of ligatures applied to the nerve $16 \mathrm{~h}$ after radiolabelling to the total radioactivity in the nerve $40-50 \mathrm{~mm}$ from the ganglion, $8 \mathrm{~h}$ after ligation.

E. The distance from the nodose ganglion of the front of the wave of ${ }^{35} \mathrm{~S}$-labelled proteins 56 after radiolabelling. ${ }^{\text {TT }}$ The transport rate for the control animals was taken from previously published work [8].

F. The ratio of the radioactive proteins in the two $2.5 \mathrm{~mm}$ nerve pieces immediately distal to a pair of ligatures applied to the nerve $16 \mathrm{~h}$ after radiolabelling to the total radioactivity in the nerve $40-50 \mathrm{~mm}$ from the ganglion, $8 \mathrm{~h}$ after ligation.

tween control and galactose-fed rabbits (Table 1), despite galactitol and myo-inositol levels similar to those found during measurement of fast transport (Table 2).

\section{Slow transport}

The mean rate of slow transport in the galactose-fed rabbits was $23.1 \pm 2.1 \mathrm{~mm} /$ day $(n=4)$ as calculated from the position of the front of the wave of radiolabelled proteins. This is the same as the normal rate of slow transport in this nerve [8]. Nerve galactitol levels ranged from $90-300 \mu \mathrm{g} / \mathrm{g}$ in the galactose-fed animals. The fluorograms of slowly transported proteins (not shown) from galactose-fed rabbits contained the same slowly transported proteins as those from controls and provided no evidence for qualitative changes in the synthesis or axonal transport of any slowly transported proteins.
Table 2. Galactitol and myo-inositol in vagus nerves of control and galactose fed rabbits

\begin{tabular}{lll}
$\begin{array}{l}\text { Group } \\
\text { (as in Table 1) }\end{array}$ & $\begin{array}{l}\text { Galactitol } \\
(\mu \mathrm{g} / \mathrm{g} \text { wet weight })\end{array}$ & $\begin{array}{l}\text { Myo-inositol } \\
(\mu \mathrm{g} / \mathrm{g} \text { wet weight })\end{array}$ \\
\hline $\begin{array}{l}\text { A. Control } \\
\text { galactose }\end{array}$ & nd & $872 \pm 153$ \\
$53.0 \pm 50.0^{2}$ & $675 \pm 193$ \\
C. Control & - & - \\
$\quad$ galactose & $170 \pm 101$ & - \\
D. Control & nd & $805 \pm 64$ \\
galactose & $50 \pm 12^{\mathrm{a}}$ & $896 \pm 166$ \\
\hline
\end{tabular}

Galactitol and myo-inositol content of vagus nerves after feeding rabbits $50 \%$ galactose for a period of 29 days. The groups correspond to the different experimental groups outlined in Table 1. In most cases levels of galactitol were not detectable (nd) in control rabbits. ${ }^{a}$ Differences between measurements from control and galactose-fed rabbits were statistically significant at the ${ }^{a} p<0.05$ level. A dash (-) indicates that no measurement was made

Table 3. Inhibition of axonal transport by acute compression in control and galactose-fed rabbits

\begin{tabular}{lcrl}
\hline Treatment & $\begin{array}{c}\text { Transport } \\
\text { block ratio }\end{array}$ & $n$ & $p$ \\
\hline Control & $0.93 \pm 0.61$ & 10 & - \\
Galactose-fed & $12.97 \pm 20.32$ & 5 & $<0.02^{\mathrm{a}}$ \\
Control with statil & $1.37 \pm 1.31$ & 5 & ${ }^{\mathrm{a}} \mathrm{NS}$ \\
Galactose-fed with statil & $0.85 \pm 0.74$ & 5 & ${ }^{\mathrm{a} S}$ \\
& & & $<0.002^{\mathrm{b}}$ \\
\hline
\end{tabular}

Inhibition of fast axonal transport in rabbit vagus nerve by local compression at $20 \mathrm{~mm} \mathrm{Hg}$. Inhibition is expressed as a Transport Block Ratio, which is the ratio of the radioactive proteins in two pieces of nerve immediately proximal and one nerve piece within the compression zone to the total radioactive proteins in the nerve $37.5-50 \mathrm{~mm}$ from the ganglion. The effects of feeding $50 \%$ galactose for 29 days with and without $25 \mathrm{mg} / \mathrm{kg}$ daily Statil are shown as mean values $\pm S D$. Ratios are significantly different from those of acontrol or "galactose-only treated rabbits, as indicated

\section{Inhibition of fast transport by compression}

The Transport Block Ratio was used as a measurement of the extent of inhibition of fast axonal transport by nerve compression (Table 3 ). The Transport Block Ratio in control rabbits was $0.93 \pm 0.61$ (range $0.28-4.23$; $n=10$ ), while that in galactose-fed rabbits was $12.97 \pm 20.32$ (range $2.60-49.25 ; n=5$ ). The difference was significant at the $p<0.02$ level. The Transport Block Ratio in galactose-fed animals treated with Statil was $0.85 \pm 0.74$ (range $0.29-2.11 ; n=5$ ). This was significantly less than the ratio in rabbits fed galactose alone $(p<0.002)$ and was not different from the ratio in control animals. Statil had no signficant direct effect on the ratio; in control animals treated with Statil the ratio was $1.37 \pm 1.31$ (range $0.35-3.05$ ), which was not different from that in control animals without Statil.

Nerve water content in the controls was $2.02 \pm$ $0.52 \mathrm{mg}$ per $\mathrm{cm}$ of nerve; after galactose feeding it was $3.18 \pm 0.49 \mathrm{mg} / \mathrm{cm}$ (Table 4). The difference between controls and galactose-fed animals was significant at 
Table 4. Nerve water content in vagus nerve of control and galactose-fed rabbits subjected to nerve compression (as in Table 3)

\begin{tabular}{lrll}
\hline Treatment & $n$ & $\begin{array}{l}\text { Nerve water } \\
(\mathrm{mg} / \mathrm{cm} \text { nerve })\end{array}$ & $p$ \\
\hline Control & 10 & $2.02 \pm 0.52$ & - \\
Galactose-fed & 5 & $3.18 \pm 0.49$ & $<0.005^{\mathrm{a}}$ \\
Control with Statil & 5 & $2.32 \pm 0.59$ & a NS \\
Galactose with Statil & 5 & $2.47 \pm 0.77$ & ${ }^{\mathrm{a} N S}$ \\
& & & b'NS \\
\hline
\end{tabular}

Nerve water content (SD) of vagus nerves after feeding $50 \%$ galactose with and without administration of Statil. Values are significantly different from those of acontrol only or ${ }^{b}$ control rabbits treated with Statil respectively

the $p<0.005$ level. After treatment with Statil, nerve water was $2.32 \pm 0.59 \mathrm{mg} / \mathrm{cm}$ of nerve in control rabbits and $2.47 \pm 0.77 \mathrm{mg}$ in galactose-fed rabbits. Neither value was significantly different from that in control rabbits without Statil.

In the same animals, galactitol was $22.7 \pm 11.9 \mu \mathrm{g} / \mathrm{g}$ in galactose-fed animals and undetectable in controls. Myo-inositol was $152 \pm 88 \mu \mathrm{g} / \mathrm{g}$, compared with $103 \pm 39$ in controls. The increase in galactitol was significant at the $p<0.005$ level; the difference in myoinositol was not significant. In those cases, measurements were made on nerves which had been freezedried and reconstituted. Galactitol levels in nerves from control rabbits treated with Statil were undetectable; in galactose-fed rabbits treated with Statil, galactitol was $4.4 \pm 9.8 \mu \mathrm{g} / \mathrm{g}$. This was not significantly different from controls. Myo-inositol in the same two groups was $625 \pm 57 \mu \mathrm{g} / \mathrm{g}$ and $548 \pm 121 \mu \mathrm{g} / \mathrm{g}$ respectively. The difference was again not significant. In those cases nerves were not freeze-dried before measurement of galactitol or myo-inositol.

\section{Discussion}

Sidenius and Jakobsen [14] showed that galactose feeding in the rat produced changes in slow and retrograde axonal transport which were similar to those found in the streptozotocin-diabetic rat. The changes in axonal transport demonstrated in this study are not identical to those observed in the rat, i.e. we were unable to demonstrate any obvious change in slow or retrograde transport but observed a slight retardation and increased amount of fast transport. The only study of axonal transport in the sensory fibres of the rabbit vagus in diabetes [15] led to the conclusion that both fast and slow axonal transport were unaffected.

The slight retardation in fast transport observed in this work may be a consequence of a reduced transport rate or of a delayed outflow of fast transported proteins from the nodose ganglia. A much more severely reduced fast transport rate has previously been seen in this laboratory in the sciatic nerve of the streptozotocin-diabetic rat [16], an effect which has subsequently been ascribed to reduced nerve temperature [17]. Although body temperature remained constant throughout these experiments, nerve temperature was not measured. The apparent increase in the amount of fast transported proteins after galactose feeding was unexpected. This could not be ascribed to a difference between the two groups in radiolabelling of proteins within the nodose ganglion. However, the possibility of increased diffusion and local incorporation of radioisotope in the galactose-fed rabbits must be considered as a contributory factor, in view of the increased water content.

Whether the differences in these results between rat and rabbit depend on the difference in the species and type of nerve studied (i.e. non-myelinated as distinct from myelinated) or on the regime for administering the galactose is unclear. At least in the streptozotocindiabetic rat, axonal dwindling is known to be confined to myelinated fibres and to be absent in non-myelinated fibres [18]. The 4-day break employed in this study to prevent weight loss may have been sufficient to restore axonal transport deficits to normal since it is known that galactitol and nerve water content can be restored to normality in the rat as early as two days after cessation of a galactose diet [19]. The higher than average nerve galactitol in the animals used for slow transport measurements in this study may reflect that fact, since those animals were restored to their galactose diet for a full $56 \mathrm{~h}$ after surgery. If that were correct, further work with galactose feeding for longer periods may be necessary to detect axonal transport defects in rabbit vagus nerve. However, it does mean that the model is suitable for studying the susceptibility of transport to compression without changes in transport per se which could complicate the calculation of the results.

Nerve galactitol levels were markedly elevated in the vagus nerve in all experiments. The values quoted above in the nerves of rabbits used for measurements of fast transport rate were typical of the values found throughout; the fact that galactitol and myo-inositol levels were low in the experiments involving nerve compression in the absence of Statil was almost certainly a consequence of the fact that it was necessary to measure galactitol and myo-inositol in the same nerves which had been freeze-dried for measurement of nerve water content and then re-constituted. This also led to a loss of myo-inositol even in nerves from control animals [20].

The increased susceptibility to compression can therefore be explained in terms of the elevated levels of sugar alcohols. In rat sciatic nerve after galactose feeding, these generate osmotic changes leading to increased water content, and a resulting increase in intercapillary distance $[4,21]$. It is this increase in intercapillary distance which is thought to be responsible for reduced endoneurial oxygen tension, and possibly reduced nerve blood flow $[22,23]$. 
While at early stages of galactose neuropathy there is also an increase in endoneurial fluid pressure, it has been argued that that is not in itself sufficient to cause capillary closing and thereby lead to ischaemia [24].

So far no morphological data is available on the changes in rabbit vagus nerve produced by galactose feeding. The elevated nerve water content and the increased galactitol do, however, suggest that the situation is similar to that found in rat sciatic nerve. Further work will be necessary to determine whether the significant influence of the galactose feeding was a compromised nerve blood flow or an elevated endoneurial fluid pressure.

The altered susceptibility of the fast transport process to local mild pressure is consistent with previous work in the streptozotocin-diabetic rat $[1,2]$; the results confirm that the effect can be observed in small nonmyelinated sensory nerve fibres of the vagus nerve. However, in rat and rabbit sciatic nerve there is conflicting evidence for and against an increased nerve water content $[5,6,25,26]$. Nor in our own experiments have we been able to observe reduced nerve myo-inositol [2] despite other reports of reductions in myo-inositol in both diabetic and galactosaemic rat nerve $[6,20]$, and the argument that changes in myo-inositol underlie the development of neuropathy and its prevention by inhibitors of aldose reductase [27] in experimental diabetes. It is likely that reduced nerve blood flow and the ensuing, or associated endoneurial hypoxia in both the galactose-fed animal and the streptozotocin-diabetic rat [21-23] are amplified in the presence of applied mild pressure, which also impairs nerve blood flow, to the extent that the oxygen-dependent fast axonal transport is inhibited [28, 29]. The relationship between elevated nerve polyols and reduced nerve blood flow may, however, be different in the two models.

Inhibition of fast axonal transport is unlikely in itself to be the explanation for longer term changes in nerve function associated with diabetes or galactose feeding [30-32]. In fact recent evidence points to deficiencies in provision of slowly transported neurofilaments [33] in galactose neuropathy. Inhibition of fast axonal transport by pressure as measured in this study is, however, known to be associated with an equivalent inhibition of slow and retrograde transport $[13,34]$.

Acknowledgements. This work was supported by a grant from the Medical Research Council, UK and Imperial Chemical Industries plc, UK. The author is grateful for the technical assistance of Ms. A. Smith, Mr. N. Hughes and Mr. D. Trafford and to Mr. D. Mirrlees for analysis of polyols.

\section{References}

1. Dahlin LB, Meiri KF, McLean WG, Rydevik B, Sjöstrand J (1986) Effects of nerve compression on fast axonal transport in streptozotocin-induced diabetes mellitus. Diabetologia 29: 181. 185
2. Dahlin LB, Archer ISR, McLean WG (1987) Treatment with an aldose reductase inhibitor can reduce the susceptibility of fast axonal transport following nerve compression in the streptozotocindiabetic rat. IDiabetologia 30: 414-418

3. Stewart MA, Sherman WR, Kurien MM, Moonsammy GI, Wisgerhof $\mathrm{M}$ (1967) Polyol accumulations in nerve tissues of rats with experimental diabetes and galactosaemia. J Neurochem 14 : 1057-1066

4. Myers RR, Costello ML, Powell HC (1979) Increased endoneurial fluid pressure in galactose neuropathy. Muscle Nerve 2: 299-303

5. Jakobsen J (1978) Peripheral nerves in early experimental diabetes. Expansion of the endoneurial space as a cause of increased water content. Diabetologia 14: $113 \cdot 119$

6. Powell HC, Costello ML, Myers RR (1981) Endoneurial fluid pressure in experimental models of diabetic neuropathy. $\mathrm{J}$ Neuropathol Exp Neurol 40: 613-624

7. Willars GB, Lambourne JE, Tomlinson DR (1987) Does galactose feeding provide a valid model of consequences of exaggerated polyol pathway flux in peripheral nerve in experimental diabetes? Diabetes $36: 1425-1431$

8. McLean WG, Frizell M, Sjöstrand J (1976) Slow axonal transport of labelled proteins in sensory fibres of rabbit vagus nerve. $J$ Neurochem 26: 1213-1216

9. Dahlin LB, Rydevik B, McLean WG, Sjöstrand J (1980) Changes in axonal transport during experimental nerve compression: critical pressure level for impairment. Exp Neurol 87: 29-36

10. Rydevik B, McLean WG, Lundborg G, Sjöstrand J (1980) Blockage of axonal transport induced by acute, graded compression of the rabbit vagus nerve. J Neurol Neurosurg Psychiat 43: 690-698

11. McLean WG, McKay $\Lambda$ L, Sjöstrand J (1983) Electrophoretic analysis of axonally transported proteins in rabbit vagus nerve. $J$ Neurobiol 14: 227-236

12. Stribling D, Mirrlees DJ, Harrison HE, Earl DCV (1985) Propertics of 128436 , a novel aldose reductase inhibitor and its effects on diabetic complications in the rat. Metabolism 34: 336-344

13. Dahlin LB, Sjöstrand J, McLean WG (1986) Graded inhibition of retrograde axonal transport by compression of rabbit vagus nerve. J Neurol Sci 76: 221-230

14. Sidenius P, Jakobsen J (1980) Axonal transport in rats after galactose feeding. Diabetologia 19: 229. 233

15. Bajada S, Sharma AK, Thomas PK (1980) Axoplasmic transport in vagal afferent fibres in normal and alloxan-diabetic rabbits. $J$ Neurol Sci 47: $365-378$

16. Meiri KF, McLean WG (1982) Axonal transport of proteins in motor fibres of experimentally diabetic rats - fast anterograde transport. Brain Res 238: 77.88

17. Whiteley SJ, Townsend J, Tomlinson DR, Brown AM (1985) Fast orthograde axonal transport in sciatic motoneurones and nerve temperature in streptozotocin-diabetic rats. Diabetologia 28 : $847-851$

18. Jakobsen J (1979) Early and preventable changes of peripheral nerve structure and function in insulin-deficient diabetic rats. $J$ Neurol Neurosurg Psychiat 42: 509-518

19. Gabbay KH, Snider JJ (1972) Nerve conduction deficit in galactose-fed rats. Diabetes 21: 295-300

20. Yue DK, Hanwell MA, Satchell PM, Handelsman DJ, Turtle JR (1984) The effect of aldose reductase inhibition on nerve sorbitol and myoinositol concentrations in diabetic and galactosemic rats. Metabolism 33: 119..122

21. Tuck RR, Schmelzer JD, Low PA (1984) Endoneurial blood flow and oxygen tension in the sciatic nerves of rats with experimental diabetic neuropathy. Brain 107: 935-950

22. Low PA, Nukuda H, Schmelzer JI), Tuck RR, Dyck PJ (1985) Endoneurial oxygen tension and radial topography in nerve edema. Brain Res 341: 147-154

23. McManis PG, Low PA, Yao JK (1986) Nerve blood flow and intercapillary distance in peripheral nerve cdema. Am $\mathrm{J}$ Physiol 251: E92-E97

24. Low PA, Dyck PJ, Schmelzer JD (1980) Mammalian peripheral 
nerve sheath has unique responses to chronic elevations of endoneurial fluid pressure. Exp Neurol 70: 399-406

25. Greene DA, Winegrad AJ (1981) Effects of acute experimental diabetes on composite energy metabolism in peripheral nerve axons and Schwann cells. Diabetes 30: 967-974

26. Malone J, Harvey R, Benford S, Mandlow S (1985) Taurine deficiency in the sciatic nerve and lens of streptozotocin-diabetic rats. Diabetes 34: 102A

27. Greene DA, Lattimer SA (1984) Action of sorbinil in diabetic peripheral nerve: relationship of polyol (sorbitol) pathway inhibition to a myo-inositol-mediated defect in sodium-potassium ATPase activity. Diabetes 33: 712-716

28. Rydevik B, Lundborg G, Bagge U (1981) Effects of graded compression on intraneural blood flow. An in vivo study on rabbit tibial nerve. J Hand Surg 6: 3-12

29. Leone J, Ochs S (1978) Anoxic block and recovery of axoplasmic transport and electrical excitability of nerve. J Neurobiol 9: 229-245

30. Myers RR, Powell HC (1984) Galactose neuropathy: impact of chronic endoneurial edema on nerve blood flow. Ann Neurol 16: 587-594

31. Tomlinson DR, Mayer JH (1984) Defects of axonal transport in diabetes mellitus - a possible contribution to the aetiology of diabetic neuropathy. J Auton Pharmacol 4: 59-72

32. Jakobsen J, Sidenius P, Braendgaard H (1986) A proposal for the classification of neuropathies according to their axonal transport abnormalities. J Neurol Neurosurg Psychiatry 49: 986-990

33. Nukada H, Dyck PJ, Low PA, Lais AC, Sparks MF (1986) Axonal caliber and neurofilaments are proportionately decreased in galactose neuropathy. J Neuropath Exp Neurol 45: 140-150

34. Dahlin LB, McLean WG (1986) Effects of graded experimental nerve compression on slow and fast axonal transport in rabbit vagus nerve. J Neurol Sci 72: 19-30

Received: 1 February 1988

and in revised form: 28 April 1988

\section{Dr. W.G. McLean}

Department of Pharmacology and Therapeutics

University of Liverpool

P.O. Box 147

Liverpool L69 3BX

UK 